\title{
MODELLING THE FINITE STRAIN BEHAVIOUR OF UNIDIRECTIONAL COMPOSITES: AN INVARIANT-BASED MODEL WITH VISCOUS EFFECTS
}

\author{
Igor A. Rodrigues Lopes ${ }^{1 *}$, Pedro P. Camanho ${ }^{1}$ and Francisco M. Andrade Pires ${ }^{1}$ \\ ${ }^{1}$ Faculty of Engineering, University of Porto, Portugal \\ *ilopes@fe.up.pt
}

The mechanical behaviour of unidirectional composites is usually modelled under the assumption of infinitesimal strains. Even though this assumption is valid for most applications involving composites based on thermoset polymers, it may become questionable when thermoplastics are employed in the composite matrix.

An invariant-based constitutive model at finite strains has been developed taking into account visco-elastic and visco-plastic effects. It is based on the multiplicative decomposition of the deformation gradient and the definition of the isoclinic configuration [1] being the result of the extension of a small strain model [2] to a finite strain framework. It is implemented for a finite element solution and the numerical results are compared to available experimental data.

\section{References}

[1] Dean, A., Sahraee, S., Reinoso, J., and Rolfes, R. (2016). Finite deformation model for short fiber reinforced composites: Application to hybrid metal-composite clinching joints. Composite Structures, 151, 162-171.

[2] Gerbaud, P. W., Otero, F., Bussetta, P., and Camanho, P. P. (2019). An invariant based transversely-isotropic constitutive model for unidirectional fibre reinforced composites considering the matrix viscous effects. Mechanics of Materials, 138, 103-146. 